Review Article

\title{
Fibrodysplasia Ossificans Progressiva: A Review with Presentation of a Case with Temporomandibular Extra-Articular Ankylosis
}

\author{
Cárcamo Idiáquez Osmar Adán ${ }^{1, ~}{ }^{\text {, }}$, Cortes Flores Michelle ${ }^{2}$, Anchecta Castro Diana Marielos ${ }^{3}$, \\ Vivanco Pérez Israel ${ }^{1}$, Navarro Zarate Adolfo ${ }^{1}$ \\ ${ }^{1}$ Maxillofacial Surgery Department, Meritorious Autonomous University of Puebla, Puebla, Mexico \\ ${ }^{2}$ Maxillofacial Surgery Department, Mexican Institute of Social Security, Guadalajara, Mexico \\ ${ }^{3}$ Faculty of Stomatology, Meritorious Autonomous University of Puebla, Puebla, Mexico
}

Email address:

mr.oaci@live.com (C. I. O. Adán)

${ }^{*}$ Corresponding author

\section{To cite this article:}

Cárcamo Idiáquez Osmar Adán, Cortes Flores Michelle, Anchecta Castro Diana Marielos, Vivanco Pérez Israel, Navarro Zarate Adolfo. Fibrodysplasia Ossificans Progressiva: A Review with Presentation of a Case with Temporomandibular Extra-Articular Ankylosis. International Journal of Clinical Oral and Maxillofacial Surgery. Vol. 4, No. 1, 2018, pp. 4-10. doi: 10.11648/j.ijcoms.20180401.12

Received: January 31, 2018; Accepted: February 16, 2018; Published: March 19, 2018

\begin{abstract}
Fibrodysplasia Ossificans Progressiva (FOP) is a connective tissue disorder that progressively affects tendons, ligaments, aponeurosis, fasciae and muscles which undergo fibrous cell proliferation that progresses to mature bone. It has a prevalence of 1 case per 2 million habitants, having reported less than 1000 cases worldwide. In the maxillofacial region, it might originate extra-articular temporomandibular ankylosis by ossification of ligaments, muscles of the mastication, head and a neck muscles; the most commonly affected are the masseters and sternocleidomastoids. The purpose of this article is to review the Fibrodysplasia Ossificans Progressiva (FOP) and to present the case of a 12-year-old male patient with FOP that causes extra-articular temporomandibular ankylosis. There is no effective proven treatment or prevention and the life expectancy of these patients approaches the 40 years of age, so the management of patients with FOP must be performed with a multidisciplinary approach in which the various health professionals work in a coordinated and joint way to offer a better quality of life to these patients and thus better understand the progression of the disease.
\end{abstract}

Keywords: Fibrodysplasia Ossificans Progressiva, Myositis Ossificans Systemic, Munchmeyer's Disease, Extra-Articular Temporomandibular Ankylosis, Ankylosis of the Temporomandibular Joint

\section{Introduction}

The Fibrodysplasia Ossificans Progressiva (FOP), also known as Myositis Ossificans Progressive, Myositis Ossificans Systemic, Fibrodysplasia Ossificans Progressiva Idiopathic, Munchmeyer's Disease and Stone Man's Disease. $[1,2]$ Initially described by a French doctor, Guy Patin in 1648 , who reported a patient "who became wood". [7] In 1736 the English surgeon John Freke, describes the case of a child of 14 years old with "ramifications of coral do in his back". [3] The term FOP was introduced by Bauer and Bode in 1940. [8] The dominant autosomal inheritance was first described by
Simpson, but it was Eileen M. Shore and Frederick S. Kaplan in 2006 that discovered the gene and the mutation that cause it. $[6,9,10]$

It is a genetic disease characterized by a connective tissue disorder that progressively affects tendons, ligaments, aponeurosis, fasciae and muscles, which undergo a fibrous cell proliferation that progresses to mature bone, is the most catastrophic heterotopic ossification disorder that occurs in humans. [2 - 6] Ossification follows a cephalo-caudal, proximal-distal, dorsal-ventral and axio-appendicular direction forming "a second skeleton", which progressively diminishes the patient's abilities, making difficult their basic 
activities such as walking, hearing, chewing, swallowing, speech and breathing which will result in an early death. [2, 10 14, 25, 26] Characteristically it respects smooth and cardiac musculature, oculomotor muscles, facial expression muscles and tongue. Its rhythm of progression is variable between the second and third decade of life, the onset is reported between 5 and 25 years old. It has a prevalence of 1 case for every $2,000,000$ habitants, it is estimated that there are around 3,500 people with FOP worldwide, but only less than 1,000 cases have been reported, it has no predilection between sex, race or geographic location. [6, 10] There are less than 10 multi-generational families worldwide $[3,4]$ and cases have been reported with exclusive compromise of the maxillofacial region. [22]

It has an autosomal dominant pattern in $10 \%$ of the cases, but most patients $(90 \%)$ correspond to a spontaneous "de novo" mutation in the gene that codes for the Activin A type I receptor like Activin- Kinase-2 (ACVR1 / ALK2) located on chromosome 2 (2q23-24). The ACVR1 / ALK2 receptor belongs to the family of bone morphogenetic protein (BMP) receptors, members of the superfamily of transforming growth factors beta (TGF- $\beta$ ). $[2,4,10,11,12]$ The predisposition to develop heterotopic bone is due to the ACVR1 mutation (c.617G> A; R206H) which consists of a substitution of a "G" base (guanine) for a " A "(adenine) at position 617, which in turn causes the replacement of the nucleotide Arginine by Histidine at codon 206. This mutation causes the ACVR1/ ALK2 gene to be permanently activated, which causes an increase in the signaling in the cascade of the BMP especially at the level of BMP 1 and 4. Ossification will be favored by any type of trauma which will originate a microenvironment of hypoxia associated with the activation of proinflammatory cytokines such as prostaglandin E-2 (PG-E2) and tumor necrosis factor alpha. (TNF- $\alpha$ ).

This combination of factors would induce an "Endothelial-Mesenchymal Transition" (EMT) of the vascular endothelial precursor cells, giving rise to pluripotent mesenchymal cells with the capacity to differentiate into osteoblasts and chondrocytes, these pluripotent cells will be focused on the anatomical regions where the ACVR1 / ALK2 receptor is expressed. (skeletal muscle, blood vessels and cartilage) [2, 11 - 14] Genetic factors condition alterations caused during fetal development, while environmental agents associated with lifestyle (injections, vaccines, anesthetic blockages, muscle fatigue, contusions, viral diseases such as flu, etc.) determine the intensity and rate of advancement of ossification. [2, 10, 15]

The disease is not related to specific alterations in laboratory tests, so its diagnosis is clinical and is based mainly on 2 criteria: congenital malformation of the first toes and progressive heterotopic endochondral ossification. [9, 10, 23] Within the congenital malformations, we can find shortening or malformation of phalanges, metatarsals and metacarpals, as well as synostosis and clinodactyly. Heterotopic ossification in early stages of the disease manifests with some degree of soft tissue inflammation of head, neck and upper back as well as the presence of painful subcutaneous nodules which progress to heterotopic bone plaques that can trigger calcifications at the level of the temporomandibular joint (TMJ), vertebral bodies (especially at the level of C2-C7), orthotopic ankylosis of the costovertebral joints, ossification of the intercostal and paravertebral muscles, progressive spinal deformity such as kyphoscoliosis or thoracic lordosis, evident osteochondromas especially in the medial region of the tibia and a femur with a short and wide neck. [2, 3, 7, 10, 23 - 25] A small number of patients present atypical clinical features such as osteochondromatosis of the hip, degenerative joint disease of the hip, scanty scalp, mild cognitive impairment, growth retardation, cataracts, retinal detachment, glaucoma, craniopharyngioma, diffuse cerebral dysfunction with seizures, cerebral and cerebellar malformations, polyostotic fibrous dysplasia, primary amenorrhea, aplastic anemia and hypospadias. [12]

The best imaging technique to establish the diagnosis is simple radiograph, which can reveal presence or absence of ossification, in most areas the lesions will appear as light radiopaque collections within a muscle (at the beginning of the disease) or as irregular masses (at the end of the disease). [2] Computed tomography (CT) is adequate to evaluate the location and degree of participation in certain muscle groups. $[27,28]$ Ossification can be identified through a bone scintigraphy since the uptake of the isotopes (99mTc MDP [Technetium methylene diphosphate] and Thallium 201) is markedly increased in these cases and have been used as parameters of lesional activity. [9, 13]

The biopsy should be avoided as it leads to an accelerated progression of the lesion. [29] Histologically, early FOP lesions contain intense mononuclear and perivascular infiltration of macrophages, mast cells and lymphocytes. The subsequent migration of mononuclear inflammatory cells to the affected muscle precedes the generalized death of skeletal muscle. After a rapid and destructive inflammatory stage, there is an intense phase associated with angiogenesis and abundant neovascularity. Early fibroproliferative lesions are histologically indistinguishable from aggressive juvenile fibromatosis. As the lesions mature, the tissue undergoes an avascular condensation in the cartilage followed by a revascularization stage with osteogenesis in a process characteristic of heterotopic endochondral ossification. The new heterotopic bone appears histologically normal with mature lamellar bone and often contains marrow elements. Mast cells have been identified in all histological phases of the formation of FOP lesions and are found in a much higher abundance compared to normal skeletal muscle. All stages of histological development are present in an active FOP lesion, which suggests that different regions within the lesion mature at different rates. [3, 10, 27, 30]

The lack of diagnosis or a misdiagnosis is reported in $90 \%$ of cases worldwide. In the early stage, it should be differentiated from aggressive juvenile fibromatosis, lymphedema and soft tissue sarcoma. The limitation of movement and the presence of ossifications / calcifications at the radiographic level may indicate myositis ossificans traumatic, myositis ossificans neurogenic, osteoblastomas, 
osteosarcomas, chondrosarcomas, as well as mature venous hemangiomas with multiple phleboliths. FOP should be differentiated from other genetic diseases such as progressive bone heteroplasia, Albright's hereditary osteodystrophy, osteoma cutis, ankylosing spondylitis, Still's disease, rigid spine syndrome and Klippel Feil syndrome. [3, 5, 9, 10, 12, 14, 16 - 21]

Some authors recommend surgery procedure in late stages of the disease when ossification results in disability. [32] The current trend is to avoid surgical excision of the ossified parts to increase the movement of the affected region, since surgical excision areas have been observed to re-ossify and further limit mobility with a more aggressive progression. $[2,3,8,14$, 25, 31]

Attempts to slow the progression of the disease with drugs such as isotretinoin (13-cis-retinoic acid), corticosteroids, indomethacin and disodium etidronate have been ineffective. $[21,33]$ It is believed that radiotherapy at low doses may be useful for its anti-inflammatory action. [34] but the International Clinical Consortium on Fibrodysplasia Ossificans Progressiva contraindicates the surgical, radiotherapy and chemotherapy procedures for its treatment. [10] Currently, there is no proven effective prevention or treatment for FOP. [3, 10, 11]

Their life expectancy is approaching 40 years of age, longevity is reduced by the involvement of the intercostal muscles and the diaphragm which leads to respiratory failure. $[9,12]$

\section{Case Description}

12-year-old male who is referred to the Maxillofacial Surgery Department of Pediatric Hospital of the Mexican Institute of Social Security from its General Hospital of Zone (GHZ) for assessment due to limitation of oral opening with 9 months of evolution. In his antecedents of importance, he has the diagnosis of Fibrodysplasia Ossificans Progressiva
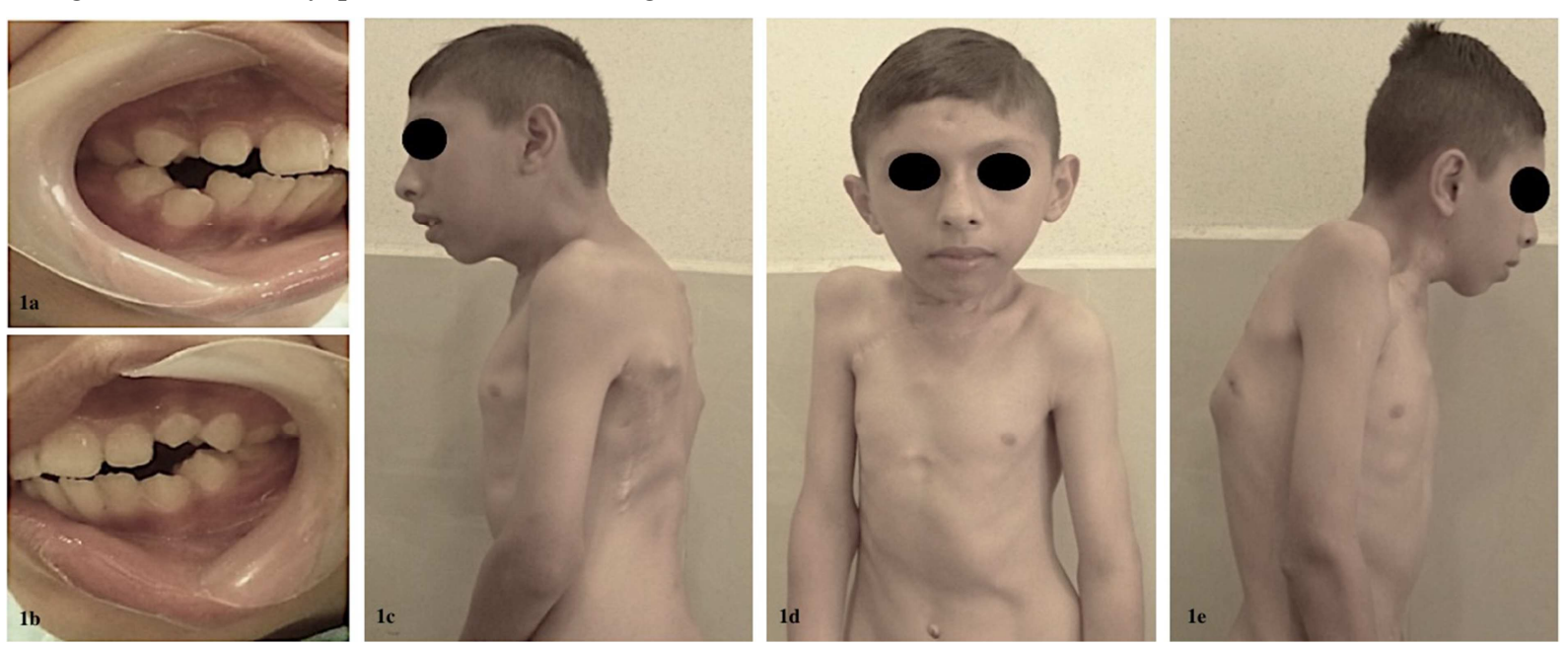

Figure 1. Intraoral photographs $1 \mathrm{a}$ and $1 \mathrm{~b}$ : right and left laterals, shows the limitation of oral opening (1mm) with bad occlusion and poor dental position is appreciated. Extraoral photographs 1c, 1d and 1e: Restriction of neck movements with an increased volume of indurated, stony consistency at the level of right SCM that compromises its entire length, with surgical scar at the level of zone II. 

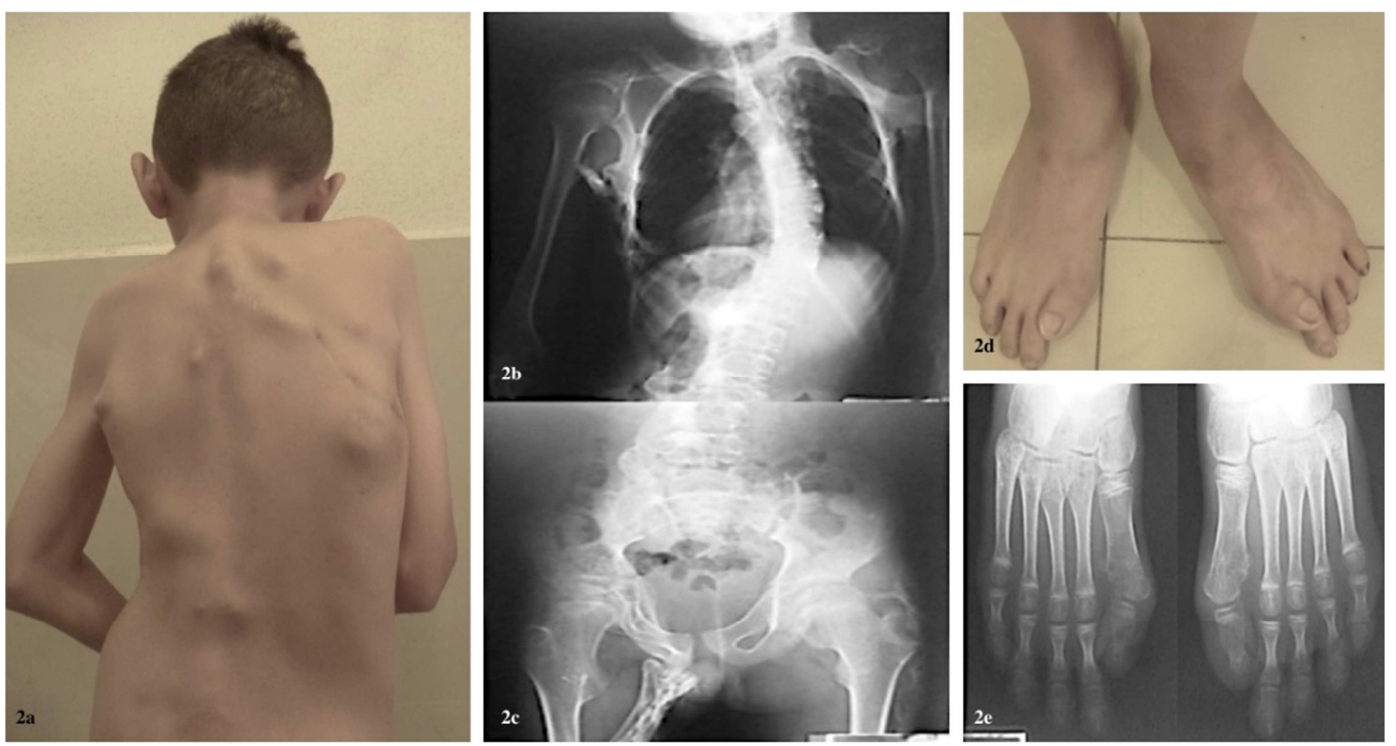

Figure 2. 2 a Multiple dorsal exostosis known as "coral branches". There is evidence of a scar from previous surgical treatment. $2 b$ and $2 c$ Simple $x$-ray of the thorax and hip that reveals multiple bony bars corresponding to heterotopic ossification at the level of the neck, thorax, spine, extremities and hips, which condition limitation of movements at the back, hip, thoracic and pelvic limbs. $2 d$ and 2e Photograph and simple x-rays of both feet showing bilateral deformity on the first toes. (hallux valgus).
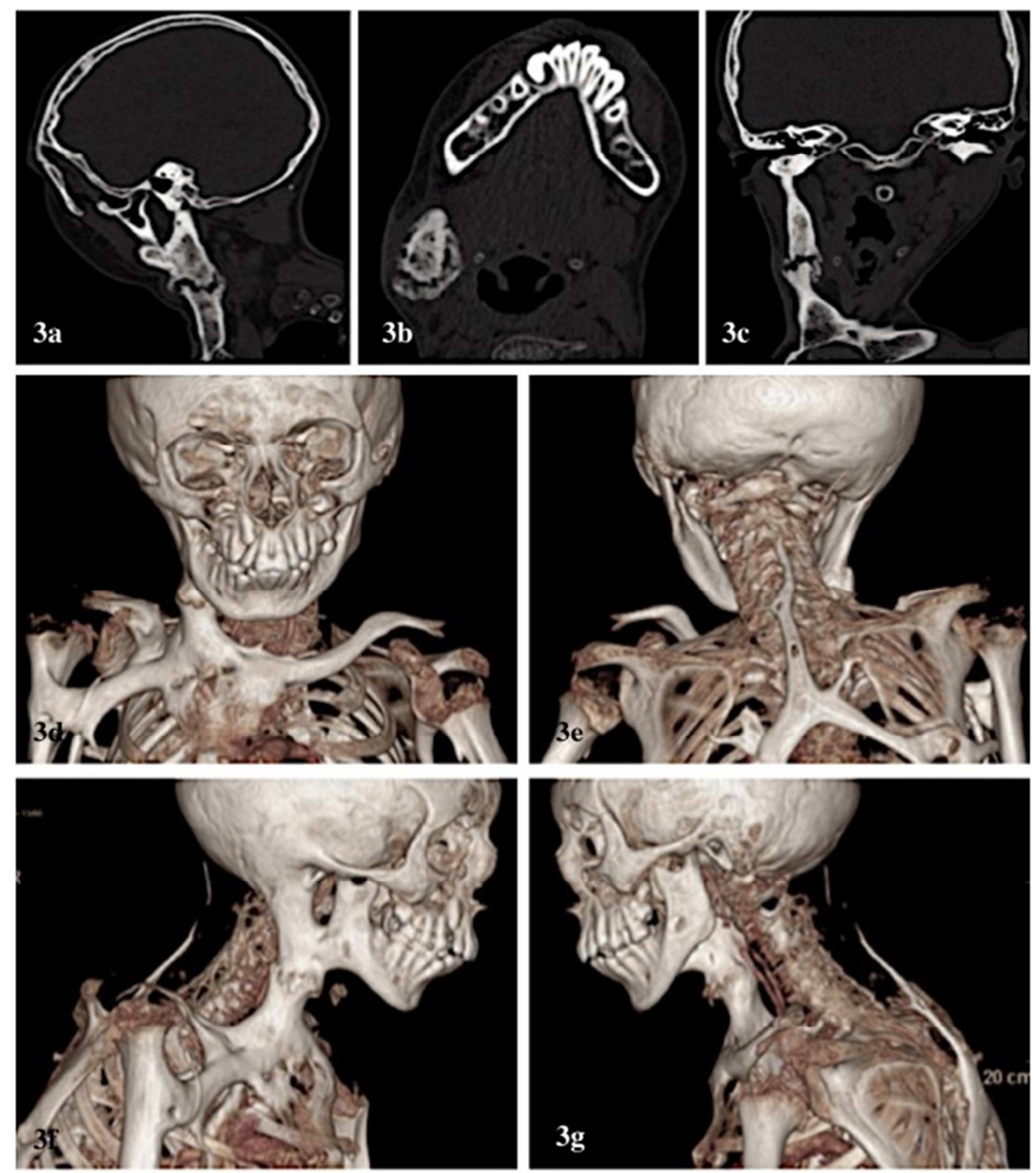

Figure 3. 3a, 3b and 3c CT of head and neck with bony window with sagittal, axial and coronal slices in which the heterotopic ossification of SCM is seen from its origin in the mastoid portion of the temporal bone until its insertion in the right clavicle and sternum, as well as its fusion with the right mandibular angle. $A$ heterogeneous image was seen at the level of the middle third of the corresponding SCM with the area where the patient was biopsied. The anatomy of the TMJ is appreciated without apparent alteration. $3 d, 3 e, 3 f$ and $3 g$ CT-3D in which the ossification of SCM and the formation of heterotopic bone bars or bridges are observed at the zygomatic apophysis of the temporal bone, mandibular angle, clavicle, sternum, scapula, humerus on the right side, as well as in the dorsal region. 


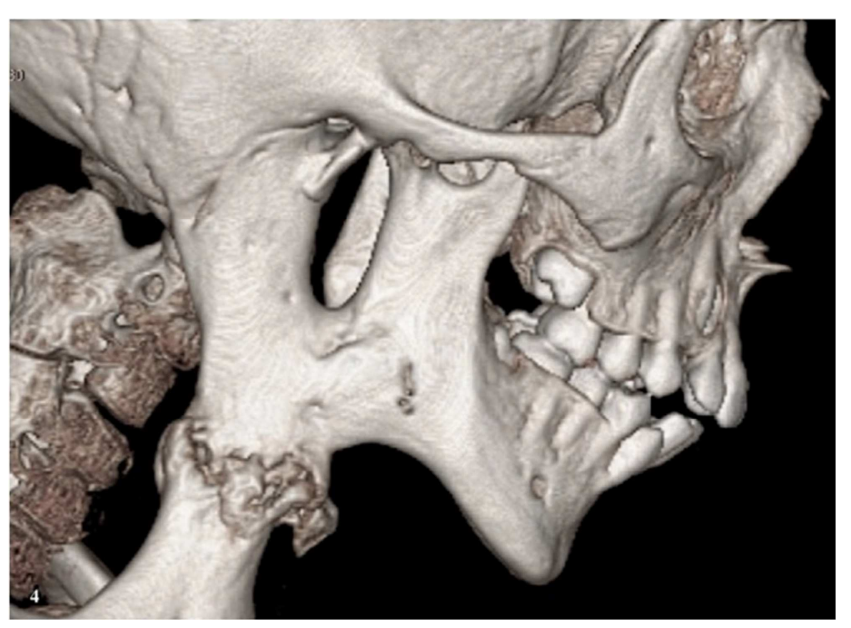

Figure 4. CT-3D in which the ossification of the SCM and the formation of a heterotopic bone bridge between SCM and the right mandibular angle and another between SCM and the zygomatic apophysis of the ipsilateral temporal bone is observed. The zone corresponding to the previous biopsy site on the middle third of the SCM is appreciated.

\section{Discussion}

Patients with FOP may present alterations in the maxillofacial region such as heterotopic ligament calcifications, also calcifications of chewing muscles, head and neck muscles and extra-articular ankylosis of the TMJ. The most commonly affected head and neck muscles are the masseter and sternocleidomastoid muscles. (Connor and Evans 1982) [35], (Renton et al., 1982) [36], (Herford and Boyne 2003) [7], (Carvalho et al., 2011) [28], (Kriegbaum and Hillerup 2013) [31], (Sellami et al., 2015) [37]

TMJ's are the last joints affected, however, approximately $80 \%$ of patients with FOP have restricted mandibular movements when 18 years old [7,8]; this restriction of movement can be presented in a spontaneous way (Sendur and Gurer 2006) [14] or post-traumatic (Luchetti et al., 1996) [15] causing a severe disability that leads to alterations in phonation, breathing, chewing, swallowing, as well as dentofacial deformities. [38] Temporomandibular ankylosis is an important complication in FOP that can trigger eating problems with severe weight loss until death because of starvation. [6, 31]

Emphasis should be done on preventive oral health measures such as periodic dental check-ups, use of toothpaste with fluoride, antimicrobial rinses, as well as fluoridated water especially during childhood to prevent long-term complications such as periodontal diseases, tooth decay, dental infectious processes, among others, since these complications will require more complex treatments and due to the limitation of the oral opening secondary to the progression of the FOP and to the reduced options of local anesthesia it is necessary to treat these patients under general anesthesia. (Singh et al., 2003) [39], (Nussbaum et al., 2005) [40], (Young et al., 2007) [41], (Nussbaum 2009) [42], (Shimono et al., 2014) [43]

An increase in soft tissue volume at the submandibular level must be addressed in a priority manner due to its potential to cause dyspnea and dysphagia that can lead to the death of the patient. The increase in volume at this level can be confused mainly with cervico-facial infectious processes, as well as with mumps, angioneurotic edema, infectious mononucleosis or neoplasms. (Lasry et al., 2005) [24], (Sellami et al., 2015) [37], (Janoff et al., 1996) [44], (Leavitt et al., 2009) [45], (Awais et al., 2015) [46] Effective treatment includes early identification of submandibular volume increase caused by FOP, nutritional support, glucocorticoid therapy, monitoring, and airway protection. Surgical manipulation of the submandibular region should be avoided because this will worsen the clinical problems of inflammation and accelerate the formation of heterotopic bone. (Janoff et al., 1996) [44]

In the presence of an increase in soft tissue volume at the submandibular level, the International Clinical Consortium on FOP recommends the following: [10]

1. All physicians treating patients with FOP should be aware that an acute volume increase at the submandibular level may be a manifestation of the disease at any age.

2. The diagnosis of FOP should be communicated to the attending physician so that the submandibular lesion can be managed in the context of the patient's underlying disease.

3. Injury handling should be avoided because even minor trauma can lead to a catastrophic exacerbation with compromised airway.

4. Patients should sleep semi-fowler to reduce the risk of airway obstruction.

5. Patients should be monitored during the acute inflammation phase, they should be hospitalized immediately in case of airway obstruction.

6. The food must be mashed or semi-solid. Fluids often cause episodes of suffocation due to the compromise of the muscles of the floor of the mouth.

7. Patients should be encouraged to eat frequently to minimize weight loss. High-calorie food supplements should be considered.

9. Precautions should be taken to prevent food aspiration.

10. High-dose oral glucocorticoids should be considered in the early treatment of acute submandibular out brakes. The glucocorticoid of choice is prednisone, $2 \mathrm{mg} / \mathrm{kg}$ body weight (up to $100 \mathrm{mg}$ ) orally once a day for four days. If it is used a second course of four days of high doses of glucocorticoids, these should be slowly lowered during the next two to three weeks. After discontinuation of glucocorticoid therapy, NSAIDs can be considered for the next 6-8 weeks.

\section{Conclusions}

The case we present is considered a sequel due to an exacerbation of FOP by the surgical procedure performed 2 years previously, which resulted in a temporo mandibular extra-articular ankylosis with severe limitation of jaw movements, which caused problems of nutrition, oral hygiene, as well as dental problems (bad occlusion, crowding, dental caries among others). Multidisciplinary management was 
initiated by physical rehabilitation, pediatric dentistry, psychology, as well as nutrition for its integral management. On our part, conservative management with periodic reviews was decided.

The maxillofacial surgeon must know the risks of a surgical treatment in patients with FOP and it is necessary to guide the patient in the care of their temporomandibular joints, oral health care and periodic dental check-ups to avoid later major complications.

Currently, there is no effective therapy to prevent or treat FOP, that is why the management must be carried out with a multidisciplinary approach in which diverse health professionals work in a coordinated and joint way to provide a better quality of life for these patients and have a better understanding in the progression of the disease.

\section{Compliance with Ethical Standards Funds}

The authors declare that they have not received any type of monetary support for the realization of this case report.

\section{Conflict of Interests}

The authors declare that they have no conflicts of interest.

\section{Ethical Approval}

The authors declare that for this case report no experiments have been conducted on humans or animals. The authors declare that patient data does not appear in this article.

\section{Informed Consent}

Informed consent of the patient was obtained for the publication of this case report and any attached image. A copy of the written consent is available, at any time, for review by the editor of this journal.

\section{References}

[1] Pignolo RJ, Shore EM and Kaplan FS. Fibrodysplasia ossificans progressiva: diagnosis, management, and therapeutic horizons. Pediatric endocrinology reviews 10 (02): 437-446, 2013.

[2] Morales-Piga A, Bachiller-Corral FJ and Sánchez-Duffhues G. ¿Es la «fibrodisplasia osificante progresiva» una enfermedad de origen vascular? Un modelo patogénico innovador. Reumatología Clínica 10 (6): 389-395, 2014.

[3] Kaplan FS, Le Merrer M, Glaser DL, Pignolo RJ, Goldsby RE, Kitterman JA and Shore EM. Fibrodysplasia ossificans progressiva. Best practice \& research Clinical rheumatology, 22 (1): 191-205, 2008.

[4] Shore EM and Kaplan FS. Insights from a rare genetic disorder of extra-skeletal bone formation, fibrodysplasia ossificans progressiva (FOP). Bone, 43 (3): 427-433, 2008.
[5] Wiggins RL, Thurber D, Abramovitch K, Bouquot $\mathrm{J}$ and Vigneswaran N. Myositis ossificans circumscripta of the buccinator muscle: first report of a rare complication of mandibular third molar extraction. Journal of oral and maxillofacial surgery, 66 (9): 1959-1953, 2008.

[6] García-Serrano G, Sagüillo K, Almeida F, Núñez J and Picón M. Fibrodisplasia osificante progresiva: el papel del cirujano oral y maxilofacial. Experiencia en 2 casos. Revista Española de Cirugía Oral y Maxilofacial, 36 (2): 73-77, 2014.

[7] Herford AS and Boyne PJ. Ankylosis of the jaw in a patient with fibrodysplasia ossificans progressiva. Oral Surgery, Oral Medicine, Oral Pathology, Oral Radiology, and Endodontology, 96 (6): 680-684, 2003.

[8] Meij EH, Becking AG and Waal I. Fibrodysplasia ossificans progressiva. An unusual cause of restricted mandibular movement. Oral diseases, 12 (2): 204-207, 2006.

[9] Díaz-de la Torre J. Fibrodisplasia osificante progresiva. Reporte de un caso. Acta Ortopédica Mexicana, 26 (3): 192-196, 2012.

[10] Kaplan FS, Shore EM, Glaser DL and Emerson S. The medical management of fibrodysplasia ossificans progressiva: current treatment considerations. In Clin Proc intl clin consort FOP, 4: $1-100,2011$.

[11] Katagiri T. Recent topics in fibrodysplasia ossificans progressiva. Journal of Oral Biosciences, 54 (3): 119-123, 2012.

[12] Pignolo RJ, Shore EM and Kaplan FS. Fibrodysplasia ossificans progressiva: clinical and genetic aspects. Orphanet journal of rare diseases, 6 (1): 80, 2011.

[13] Hernández GS, Ruiz AM, Río MG, Fernandez AR, Lozano SO, Font CR and Elvira JL. Miositis osificante progresiva. Utilidad de la gammagrafía ósea. Revista Española de Medicina Nuclear, 24 (3): 195-198, 2005.

[14] Sendur OF and Gurer G. Severe limitation in jaw movement in a patient with fibrodysplasia ossificans progressiva: a case report. Oral Surgery, Oral Medicine, Oral Pathology, Oral Radiology and Endodontics, 102 (3): 312-317, 2006.

[15] Luchetti W, Cohen RB, Hahn GV, Rocke DM, Helpin M, Zasloff $M$ and Kaplan FS. Severe restriction in jaw movement after routine injection of local anesthetic in patients who have fibrodysplasia ossificans progressiva. Oral Surgery, Oral Medicine, Oral Pathology, Oral Radiology, and Endodontology, 81 (1): 21-25, 1996.

[16] Woolgar JA, Beirne JC and Triantafyllou A. Myositis ossificans traumatica of sternocleidomastoid muscle presenting as cervical lymph-node metastasis. International journal of oral and maxillofacial surgery, 24 (2): 170-173, 1995.

[17] Jayade B, Adirajaiah S, Vadera H, Kundalaswamy G, Sattur AP and Kalkur C. Myositis ossificans in medial, lateral pterygoid, and contralateral temporalis muscles: a rare case report. Oral surgery, oral medicine, oral pathology and oral radiology, 116 (4): 261-266, 2013

[18] Mevio E, Rizzi L and Bernasconi G. Myositis ossificans traumatica of the temporal muscle: a case report. Auris Nasus Larynx, 28 (4): 345-347, 2001.

[19] Saka B, Stropahl G and Gundlach KKH. Traumatic myositis ossificans (ossifying pseudotumor) of temporal muscle. International journal of oral and maxillofacial surgery, 31 (1): 110-111, 2002. 
[20] Aoki T, Naito H, Ota Y and Shiiki K. Myositis ossificans traumatica of the masticatory muscles: review of the literature and report of a case. Journal of oral and maxillofacial surgery, 60 (9): 1083-1088, 2002.

[21] Kim DD, Lazow SK, Har-El G and Berger JR. Myositis ossificans traumatica of masticatory musculature: a case report and literature review. Journal of oral and maxillofacial surgery, 60 (9): 1072-1076, 2002.

[22] Debeney-Bruyerre C, Chikhani L, Lockhart R, Favre-Dauvergne E, Weschler B, Bertrand JC and Guilbert F. Myositis ossificans progressiva: five generations where the disease was exclusively limited to the maxillofacial region: a case report. International journal of oral and maxillofacial surgery, 27 (4): 299-302, 1998.

[23] Kaplan FS, Groppe J and Shore EM. When one skeleton is enough: approaches and strategies for the treatment of fibrodysplasia ossificans progressiva (FOP). Drug Discovery Today: Therapeutic Strategies, 5 (4): 255-262, 2009.

[24] Lasry F, Touki A, Abkari A and Khalifa HH. A rare cause of painful cervical swelling: myositis ossificans progressiva in childhood. Report of a case. Joint bone spine, 72 (4): 335-337, 2005.

[25] Morales-Piga A, Bachiller-Corral J, Trujillo-Tiebas MJ, Villaverde-Hueso A, Gamir-Gamir ML, Alonso-Ferreira V and Ayuso-García C. Fibrodysplasia ossificans progressiva in Spain: epidemiological, clinical, and genetic aspects. Bone, 51 (4): 748-755, 2012.

[26] Gómez MDMM, Navarro MN, Santiago FR and Álvarez ER. Fibrodisplasia osificante progresiva: comunicación de un caso terminal. Reumatología Clínica, 2016. http://dx.doi.org/10.1016/j.reuma.2016.04.006.

[27] Bridges AJ, Hsu KC, Singh A, Churchill R and Miles J. Fibrodysplasia (myositis) ossificans progressiva. In Seminars in arthritis and rheumatism, 24 (3): 155-164, 1994.

[28] Carvalho DR, Farage L, Martins BJAF and Speck-Martins CE. Craniofacial findings in fibrodysplasia ossificans progressiva: computerized tomography evaluation. Oral Surgery, Oral Medicine, Oral Pathology, Oral Radiology, and Endodontology, 111 (4): 499-502, 2011.

[29] Rogers JG and Geho WB. Fibrodysplasia ossificans progressiva. A survey of forty-two cases. J Bone Joint Surg Am, 61 (6): 909-914, 1979.

[30] Marx RE and Stern D. Oral and Maxillofacial Pathology: A Rationale for Diagnosis and Treatment. Inflammatory and Reactive Diseases of the Oral and Maxillofacial Region. Myositis Ossificans Progressiva. 2nd Ed. China. Quintessence Publishing Co. 2012 Chap. 2. Pag. 36-41.

[31] Kriegbaum RK and Hillerup S. Fibrodysplasia ossificans progressiva (FOP): Report of a case with extra-articular ankylosis of the mandible. Journal of Cranio-Maxillofacial Surgery, 41 (8): 856-860, 2013.

[32] Duan Y, Zhang $\mathrm{H}$ and $\mathrm{Bu}$ R. Intraoral approach technique for treating trismus caused by fibrodysplasia ossificans progressiva. Journal of Oral and Maxillofacial Surgery, 68 (6): 1408-1410, 2010.
[33] Bar Oz B and Boneh A. Myositis ossificans progressiva: a 10 year follow - up on a patient treated with etidronate disodium. Acta Paediatrica, 83 (12): 1332-1334, 1994.

[34] Hildebrandt G, Seed MP, Freemantle CN et al. Mechanisms of the antiinflammatory activity of low-dose radiation therapy. Int J Radiat Biol, 74 (3): 367-378, 1998.

[35] Connor JM and Evans DAP. Extra-articular ankylosis in fibrodysplasia ossificans progressiva. British Journal of Oral Surgery, 20 (2): 117-121, 1982.

[36] Renton P, Parkin SF and Stamp TCB. Abnormal temporomandibular joints in fibrodysplasia ossificans progressiva. British Journal of Oral Surgery, 20 (1): 31-38, 1982.

[37] Sellami M, Kallel S, Kessentini A, Charfeddine I, Hammami B and Ghorbel A. Fibrodysplasia ossificans progressiva presenting as a painful swelling of the sternocleidomastoid muscle. Journal of Oral and Maxillofacial Surgery, Medicine, and Pathology, 27 (5): 690-692, 2015.

[38] Roberts T, Stephen L, Scott C, Urban M, Sudi S and Beighton P. Fibrodysplasia ossificans progressiva (FOP) in South Africa: dental implications in 5 cases. Oral Surgery, Oral Medicine, Oral Pathology, Oral Radiology, and Endodontology, 112 (1): 11-18, 2011.

[39] Singh A, Ayyalapu A and Keochekian A. Anesthetic management in fibrodysplasia ossificans progressiva (FOP): a case report. Journal of clinical anesthesia, 15 (3): 211-213, 2003.

[40] Nussbaum BL, Grunwald Z and Kaplan FS. Oral and dental health care and anesthesia for persons with fibrodysplasia ossificans progressiva. Clinical Reviews in Bone and Mineral Metabolism, 3 (3-4): 239-242, 2005.

[41] Young JM, Diecidue RJ and Nussbaum BL. Oral management in a patient with fibrodysplasia ossificans progressiva. Special Care in Dentistry, 27 (3): 101-104, 2007.

[42] Nussbaum BL. Dental care for patients who are unable to open their mouths. Dental Clinics of North America, 53 (2): 323-328, 2009.

[43] Shimono K, Uchibe K, Kuboki T and Iwamoto M. The pathophysiology of heterotopic ossification: Current treatment considerations in dentistry. Japanese Dental Science Review, 50 (1): 1-8, 2014.

[44] Janoff HB, Zasloff MA and Kaplan FS. Submandibular swelling in patients with fibrodysplasia ossificans progressiva. Otolaryngology-Head and Neck Surgery, 114 (4): 599-604, 1996.

[45] Leavitt BD, Teeples TJ and Viozzi CF. Submandibular space swelling in a patient with fibrodysplasia ossificans progressiva: a diagnostic dilemma. Journal of Oral and Maxillofacial Surgery, 67 (3): 668-673, 2009.

[46] Awais M, Rehman A and Baloch NUA. Fibrodysplasia Ossificans Progressiva Misdiagnosed as Cervical Exostosis. Internal Medicine, 54 (7): 867-868, 2015. 